\title{
POTENCIALIDADES ENERGÉTICAS DAS MADEIRAS DE LEUCENA (LEUCAENA LEUCOCEPHALA) E PAU-JACARÉ (PIPTADENIA GONOACANTHA)
}

\author{
Potential energy of the woods Leucena (Leucaena Leucocephala) and Pau-Jacaré( Piptadenia Gonoacantha) \\ Thobias Fagundes Florindo Machado', Azarias Machado de Andrade ${ }^{2}$, Alessandro de Paula Silva ${ }^{3}$, \\ Marcelo Fonseca Monteiro de Sena ${ }^{4}$, Sérgio Thode Filho ${ }^{5}$ \\ 'Graduando de Engenharia Florestal da Universidade Federal Rural do Rio de Janeiro (UFRRJ) \\ ${ }^{2}$ Professor do Curso de Engenharia Florestal da UFRRJ \\ ${ }^{3}$ Mestrando em Ciências do Solo da UFRRJ \\ 4,5Professor do Instituto Federal do Rio de Janeiro Instituto Federal do Rio de Janeiro (IFRJ), Campus Duque de Caxias, RJ
}

\begin{abstract}
Resumo
Este trabalho objetivou a avaliação das potencialidades energéticas das madeiras de leucena (Leucaena leucocephala) e pau-jacaré (Piptadenia gonoacantha), espécies com bons índices de produtividade e interessantes características silviculturais, usando como base para comparação a madeira de eucalipto (Eucalyptus grandis). Os materiais lenhosos foram pirolisados às temperaturas de $400^{\circ} \mathrm{C}$ e $600^{\circ} \mathrm{C}$ num forno mufla devidamente adaptado. Em seguida, os rendimentos médios em carvão vegetal, em carbono fixo, gases condensáveis e incondensáveis, observados após a pirólise foram comparados entre si. A partir da análise dos dados foi possível constatar que, em termos absolutos, o maior rendimento gravimétrico médio, de 30,48\%, foi apresentado pelo carvão vegetal da lenha do pau-jacaré (Piptadenia gonoacantha), pirolisada à temperatura $400^{\circ} \mathrm{C}$ e quando pirolisada às temperaturas de $400^{\circ} \mathrm{C}$ e $600^{\circ} \mathrm{C}$, apresentaram rendimentos em carbono fixo ligeiramente superiores aos das duas outras espécies. Considerando-se que o rendimento em carbono fixo é uma variável que deriva de parâmetros qualitativos e quantitativos do carvão, pode-se concluir que o pau-jacaré ( $P$. gonoacantha), dentre as espécies analisadas, é a mais indicada para fornecer material para ser utilizado como combustível, tanto na forma de lenha como de carvão vegetal.
\end{abstract}

Palavras-chave: Leucaena leucocephala, Piptadenia gonoacantha, pirólise, carvão vegetal.

\begin{abstract}
The objective of this study was to evaluate of the energetic potentialities of leucena woods (Leucaena leucocephala) and pau-jacaré (Piptadenia gonoacantha), species with good indices of productivity and interesting silviculturais characteristics using as comparison the eucalipto wood (Eucalyptus grandis). The woody materials were pyrolysed to the temperatures of $400^{\circ} \mathrm{C}$ and $600^{\circ} \mathrm{C}$ in an oven mufla properly adapted. Soon after, the average revenues in vegetable coal, in fixed carbon, condensable gases and incondensáveis, observed after the pyrolysis were compared to each other. From the analysis of the data was possible to verify that, in terms of absolute, the biggest average gravimetric revenue, of $30,48 \%$, was introduced by the vegetable coal of the firewood of the pau-jacare (P. gonoacantha), pyrolysed to the temperature $400^{\circ} \mathrm{C}$ and when pyrolysed to the temperatures of $400^{\circ} \mathrm{C}$ and $600^{\circ} \mathrm{C}$ they introduced revenues in fixed lightly better carbon to the of the two other species. Considering itself that the revenue in fixed carbon is a variable that drift of qualitative and quantitative parameters of the coal, it can conclude that the pau-jacaré ( $P$. gonoacantha), among the analyzed species, it is in excess nominee to supply material to be used as fuel, so much in the firewood form as of vegetable coal.
\end{abstract}

Keywords: Leucaena leucocephala, Piptadenia gonoacantha, pyrolysis, vegetable coal. 


\section{INTRODUÇÃO}

O aproveitamento da madeira como fonte de energia remonta à pré-história. Com o domínio do fogo pelo homem, a lenha passou a ser usada como principal combustível. O carvão da madeira também é um combustível fabricado desde a antiguidade, já sendo comum na Gália, por ocasião da invasão romana. Os egípcios, persas e chineses faziam uso do carvão vegetal para a geração das altas temperaturas necessárias para a fabricação de armas e moedas. No Egito eram utilizados vasos fechados para a destilação de lenha e, a exemplo dos persas, fabricava-se o carvão e obtinha-se o alcatrão vegetal (ANDRADE \& CARVALHO, 1998).

Atualmente, muito se tem discutido acerca dos problemas gerados pelas freqüentes crises do petróleo, o que resulta na percepção da vulnerabilidade do planeta em relação às suas fontes energéticas. Pesquisas buscando fontes alternativas de energia têm sido desenvolvidas em vários países, visando-se, principalmente, o conhecimento de novos combustíveis derivados de fontes renováveis. Dentro deste contexto, cresce a importância da madeira para fins energéticos, quando comparada com os combustíveis fósseis. Além de renovável a madeira é menos poluente, caracterizando-se por um ciclo fechado em relação ao dióxido de carbono. Em regime de produção sustentada, o que a madeira libera de dióxido de carbono para a geração de energia a floresta consome no seu metabolismo. O mesmo não acontece com os combustíveis fósseis que lançam na atmosfera o $\mathrm{CO}_{2}$, além de outros gases, como os compostos de enxofre, que praticamente não são produzidos quando se usa a madeira. Em relação à energia da biomassa florestal, o Brasil destaca-se pelos seguintes motivos: existência de significativas extensões de terra com vocação florestal, condições excepcionais para a utilização de biomassa florestal, tecnologias disponíveis ao setor, clima favorável, alto índice solarimétrico, boa precipitação e grande potencial hídrico (ANDRADE \& CARVALHO, 1998; NOGUEIRA et al., 2000).

$\mathrm{Na}$ conversão da madeira a carvão vegetal ocorre, além da concentração de carbono, uma série de fenômenos físicos e químicos, que resultam num resíduo sólido carbonoso (carvão) e numa fração gasosa, (BRITO, 1990; ANDRADE, 1993; ANDRADE \& CARVALHO, 1998). Uma parte dessa fração gasosa pode ser condensada, permitindo a obtenção do chamado líquido pirolenhoso e a outra parte resulta em gases incondensáveis inflamáveis, a exemplo do $\mathrm{CO}, \mathrm{H}_{2}, \mathrm{CH}_{4}, \mathrm{C}_{2} \mathrm{H}_{6}$, dentre outros. O líquido pirolenhoso é constituído por água e por compostos químicos como os ácidos acético e fórmico, o éter, os álcoois metílico e etílico, a acetona, o alcatrão, furfural, formaldeídos, dentre outros componentes. De acordo com pesquisas desenvolvidas pelo projeto INFOTEC/ PRÓ-CARVÃO (2000), quando diluído em água e, ou, em urina bovina, o líquido pirolenhoso encontra uma vasta aplicação no campo das culturas orgânica e convencional. O alcatrão, em virtude da sua composição, constituída basicamente por compostos fenólicos, creosoto e piche, pode ser utilizado como combustível, como preservativo de madeira ou como uma importante matéria-prima nas indústrias química e farmacêutica.

No Brasil, cerca de $1 / 4$ de toda a energia consumida resulta da utilização da biomassa florestal, valor comparável à participação do petróleo ou da energia hidrelétrica no balanço energético nacional. Em virtude da sua importância econômica e estratégica, a energia derivada da biomassa deve ser considerada como uma alternativa de grande potencial, que pode contribuir para o abastecimento energético do País. O não cadastramento de parte da madeira consumida, per capta e por região, torna difícil uma avaliação em termos estatísticos. Entretanto, há estimativas de que mais de $50 \%$ de toda a madeira consumida no Brasil seja queimada como combustível (INFOTEC/PRÓ-CARVÃO, 2000; ABRACAVE, 2000; INFOTEC/ PRÓ-CARVÃO, 2001).

A presente pesquisa objetivou o estudo termogravimétrico das madeiras de leucena ( $L$. leucocephala) e pau-jacaré ( $P$. gonoacantha), pirolisadas às temperaturas máximas de $400 \mathrm{oC}$ e $600 \mathrm{oC}$, usando como base de comparação a madeira de eucalipto ( $E$. grandis) pirolisada sob as mesmas condições.

\section{MATERIAL E MÉTODOS}

As madeiras de eucalipto (E. grandis), leucena ( $L$. leucocephala) e pau-jacaré ( $P$. gonoacantha) foram obtidas no Campus da Universidade Federal Rural do Rio de Janeiro, em Seropédica, RJ. Após o abate, de cada árvore-amostra, com aproximadamente 7 anos de idade, foram retirados seis discos de madeira, com cerca de três centímetros de espessura, para a realização das análises físico-químicas. Os discos foram retirados nas seguintes alturas do fuste: o primeiro a $0,3 \mathrm{~m}$ do nível do solo, o segundo a 1,30m do nível do 


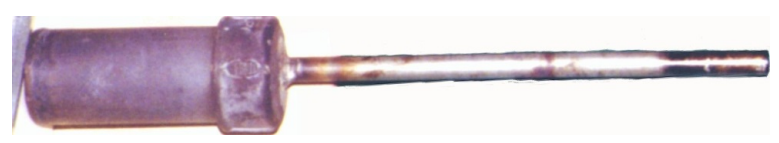

Figura 1. Cadinho metálico, utilizado durante a pirólise das matérias-primas lenhosas.

solo (altura do peito) e os quatro restantes a 25 , 50,75 e $100 \%$ da altura comercial. Em seguida, o material foi acondicionado em embalagens plásticas devidamente identificadas e encaminhado para as análises posteriores no Laboratório de Energia da Madeira do Departamento de Produtos Florestais, no Instituto de Florestas da UFRRJ.

Os seis discos de madeira com casca, coletados de cada uma das respectivas árvores-amostra, foram quarteados. Duas cunhas opostas entre si, de cada disco, foram utilizadas na determinação da densidade básica da madeira, em $\mathrm{g} / \mathrm{cm}^{3}$, pelo método hidrostático, segundo a metodologia proposta por VITAL (1984). As duas cunhas restantes foram cavaqueadas e o material resultante foi utilizado nas destilações secas (pirólise).

$\mathrm{Na}$ determinação da densidade básica da madeira promoveu-se a imersão das amostras em água até a completa saturação, o que se deu ao final de, aproximadamente, 48 horas. Em seguida, foram determinados os volumes das amostras com base nos volumes de água deslocados pelas mesmas ao serem imersas num béquer com água instalado sobre o prato de uma balança. Após a secagem das amostras, até $0 \%$ de umidade, em uma estufa regulada a $105 \pm 3^{\circ} \mathrm{C}$, relacionou-se a massa absolutamente seca com o volume saturado das amostras, determinando-se, desta forma, as respectivas densidades básicas, em $\mathrm{g} / \mathrm{cm}^{3}$.

As amostras dos materiais lenhosos foram cavaqueadas e secas até $0 \%$ de umidade em uma estufa regulada a $105 \pm 3^{\circ} \mathrm{C}$. O material a.s. (abso- lutamente seco) de cada espécie florestal foi submetido ao processo de pirólise às temperaturas máximas de $400^{\circ} \mathrm{C}$ e $600^{\circ} \mathrm{C}$.

Durante as destilações os vapores liberados foram condensados, quantificados e armazenados para as análises posteriores. O carvão vegetal, analisado qualitativa e quantitativamente, foi produzido dentro de um cadinho metálico (Figura 1) que, por sua vez, foi acondicionado dentro do forno mufla apresentado na Figura 2, devidamente adaptado para a pirólise das matérias-primas lenhosas.

Os gases incondensáveis, com alguns constituintes inflamáveis na sua composição, foram queimados na saída do sistema de arrefecimento. De posse das massas de cada um dos produtos foram obtidos os rendimentos gravimétricos em carvão, em líquido pirolenhoso e em gases incondensáveis.

Após as determinações das respectivas massas totais, amostras representativas dos carvões foram separadas, maceradas e peneiradas. Nas análises químicas subseqüentes foram utilizadas amostras com a granulometria média inferior a $1,00 \mathrm{~mm}$ e superior a $0,25 \mathrm{~mm}$, mantidas numa estufa regulada a $105 \pm 3^{\circ} \mathrm{C}$ por cerca de 48 horas. Foram efetuadas quatro análises por amostra de carvão, utilizando-se alíquotas de 1 grama, adotando-se a norma ASTM D-1762-64, modificada por OLIVEIRA et al. (1982), determinando-se os teores de matérias voláteis, de cinza e de carbono fixado no carvão vegetal.

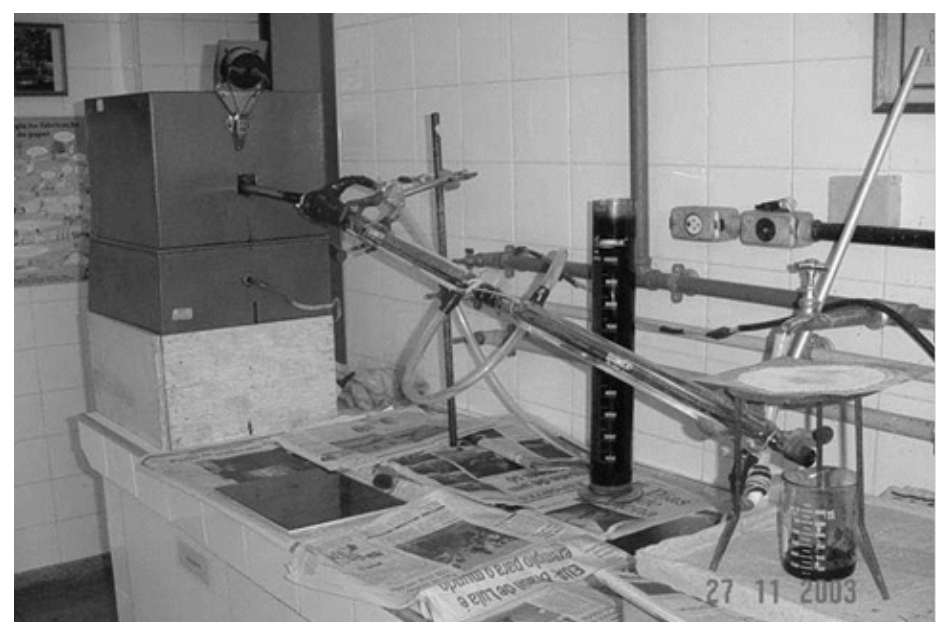

Figura 2. Sistema adaptado para a pirólise das matérias-primas lenhosas, em que: $1=$ forno mufla, $2=$ condensadores de Liebig e $3=$ recipiente para coletar o líquido pirolenhoso. 


\section{RESULTADOS E DISCUSSÃO}

Na Tabela 1 constam os valores médios das densidades básicas das espécies florestais analisadas, em $\mathrm{g} / \mathrm{cm}^{3}$.

Em termos absolutos, a maior densidade básica média foi apresentada pela madeira de pau-jacaré $\left(P\right.$. gonoacantha), de $0,56 \mathrm{~g} / \mathrm{cm}^{3}$. Para fins energéticos, quanto maior for a densidade básica da madeira melhor (ANDRADE, 1989; ANDRADE \& CARVALHO, 1998). No caso da carbonização, uma maior massa de material orgânico por unidade de volume estará sendo transformada em carbono. Portanto, se forem consideradas apenas as densidades básicas, a madeira do pau-jacaré ( $P$. gonoacantha) apresenta um maior potencial energético, em comparação com as duas outras espécies florestais analisadas.
Na Tabela 2 constam os rendimentos gravimétricos médios em carvão, gases condensáveis e gases incondensáveis, observados após a pirólise das madeiras de eucalipto (E. grandis), leucena (L. leucocephala) e pau-jacaré ( $P$. gonoacantha), às temperaturas de $400{ }^{\circ} \mathrm{C}$ e $600^{\circ} \mathrm{C}$.

Observa-se, na Tabela 2, que os valores médios dos rendimentos gravimétricos em carvão tendem a diminuir à medida que se aumenta a temperatura máxima de pirólise, confirmando as considerações de ANDRADE (1989). Os rendimentos médios em carvão apresentados pelas madeiras de pau-jacaré ( $P$. gonoacantha) e de leucena (L. leucocephala), pirolisadas à temperatura máxima de $400^{\circ} \mathrm{C}$, foram significativamente superiores aos demais. A $600^{\circ} \mathrm{C}$, também sobressaíram-se as madeiras de leucena (L. leucocephala) e pau-jacaré (P. gonoacantha).

Tabela 1. Os valores médios das densidades básicas das espécies florestais analisadas, em $\mathrm{g} / \mathrm{cm}^{3}$.

Espécie Florestal

Eucalipto
(E. grandis)
Leucena
(L. leucocephala)
Pau-jacaré
(P. gonoacantha)

Densidade $\left(\mathrm{g} / \mathrm{cm}^{3}\right)$

0,42

0,56

Tabela 2. Valores médios dos rendimentos em carvão (RGR), gases condensáveis (RGC) e gases incondensáveis (RGI), observados após a pirólise das madeiras de eucalipto (E. grandis), leucena $(L$. leucocephala) e pau-jacaré ( $P$. gonoacantha), às temperaturas de $400{ }^{\circ} \mathrm{C}$ e $600{ }^{\circ} \mathrm{C}^{*}$

\begin{tabular}{ccccc}
\hline Espécie & $\begin{array}{c}\text { Temperatura } \\
\left({ }^{\circ} \mathbf{C}\right)\end{array}$ & $\begin{array}{c}\text { RGR } \\
\mathbf{( \% )}\end{array}$ & $\begin{array}{c}\text { RGC } \\
\mathbf{( \% )}\end{array}$ & $\begin{array}{c}\text { RGI } \\
\mathbf{( \% )}\end{array}$ \\
\hline & & & & \\
Eucalipto & 400 & $29,35 \mathrm{~B}$ & $44,79 \mathrm{~A}$ & $25,85 \mathrm{~B}$ \\
(E. grandis) & 600 & $25,23 \mathrm{D}$ & $42,53 \mathrm{AB}$ & $31,27 \mathrm{~A}$ \\
\hline & & & \\
Leucena & 400 & $30,16 \mathrm{AB}$ & $42,56 \mathrm{AB}$ & $27,38 \mathrm{~B}$ \\
(L. leucocephala) & 600 & $26,87 \mathrm{C}$ & $42,88 \mathrm{AB}$ & $30,25 \mathrm{~A}$ \\
\hline & & & \\
Pau-jacaré & 400 & $30,48 \mathrm{~A}$ & $42,43 \mathrm{AB}$ & $26,89 \mathrm{~B}$ \\
(P. gonoacantha) & 600 & $26,18 \mathrm{CD}$ & $41,72 \mathrm{~B}$ & $31,70 \mathrm{~A}$ \\
& & & \\
\hline
\end{tabular}

*Letras maiúsculas diferentes, na mesma coluna, indicam diferença estatística entre os tratamentos, ao nível de 95 \% de probabilidade pelo teste de Tukey 
Tabela 3. Valores médios dos teores de matérias voláteis (TMV), cinza (TCZ), carbono fixo (TCF) e rendimento em carbono fixo (RCF) dos carvões das espécies florestais analisadas*

\begin{tabular}{cccccc}
\hline Espécie & $\begin{array}{c}\text { Temperatura } \\
\left({ }^{\circ} \mathbf{C}\right)\end{array}$ & $\begin{array}{c}\text { TMV } \\
\mathbf{( \% )}\end{array}$ & $\begin{array}{c}\text { TCZ } \\
(\mathbf{\%})\end{array}$ & $\begin{array}{c}\text { TCF } \\
\mathbf{( \% )}\end{array}$ & $\begin{array}{c}\text { RCF } \\
\mathbf{( \% )}\end{array}$ \\
\hline Eucalipto & 400 & $24,00 \mathrm{AB}$ & $2,20 \mathrm{C}$ & $73,80 \mathrm{C}$ & $21,66 \mathrm{~B}$ \\
$($ E. grandis $)$ & 600 & $10,00 \mathrm{CD}$ & $2,60 \mathrm{BC}$ & $87,40 \mathrm{~A}$ & $22,06 \mathrm{AB}$ \\
& & & & & \\
\hline & 400 & $26,00 \mathrm{~A}$ & $2,80 \mathrm{BC}$ & $71,20 \mathrm{D}$ & $21,46 \mathrm{~B}$ \\
$\begin{array}{c}\text { Leucena } \\
\text { (L. leucocephala) }\end{array}$ & 600 & $11,80 \mathrm{C}$ & $4,60 \mathrm{~A}$ & $83,60 \mathrm{~B}$ & $22,46 \mathrm{AB}$ \\
& & & & & \\
\hline & 400 & $22,60 \mathrm{~B}$ & $2,60 \mathrm{BC}$ & $74,80 \mathrm{C}$ & $22,79 \mathrm{~A}$ \\
Pau-jacaré & 600 & $9,00 \mathrm{D}$ & $3,80 \mathrm{AB}$ & $87,20 \mathrm{~A}$ & $22,83 \mathrm{~A}$
\end{tabular}

*Letras maiúsculas diferentes, na mesma coluna, indicam diferença estatística entre os tratamentos, ao nível de $95 \%$ de probabilidade pelo teste de Tukey.

Em relação aos rendimentos em gases condensáveis, o valor médio apresentado pela madeira de eucalipto (E. grandis), pirolisada a $400{ }^{\circ} \mathrm{C}(44,79 \%)$ foi $7,36 \%$ maior do que o valor médio apresentado pela madeira de pau-jacaré (P. gonoacantha), pirolisada a $600{ }^{\circ} \mathrm{C}(41,72 \%)$. Entre os demais tratamentos não foram detectadas diferenças significativas. Quando comparados entre si, rendimentos em gases incondensáveis estatisticamente superiores foram observados após as pirólises a $600^{\circ} \mathrm{C}$, para as três espécies florestais analisadas.

$\mathrm{Na}$ Tabela 3 constam os valores médios dos teores de matérias voláteis (TMV), de cinza (TCZ) e de carbono fixo (TCF), bem como os rendimentos em carbono fixo (RCF) dos carvões das espécies florestais analisadas.

A análise química imediata demonstrou, para todas as espécies florestais analisadas, que os teores de matérias voláteis nos carvões diminuem à medida que se aumenta a temperatura máxima de pirólise. Para exemplificação, o valor médio apresentado pelo carvão da madeira de leucena (L. leucocephala), pirolisada a $400{ }^{\circ} \mathrm{C}(26,00 \%)$ foi $188,89 \%$ maior do que o valor médio apresentado pelo carvão da madeira de pau-jacaré $(P$. gonoacantha), pirolisada a $600{ }^{\circ} \mathrm{C}(9,00 \%)$.

Há uma ligeira tendência ao aumento no teor de cinza no carvão à medida que se eleva a temperatura máxima de pirólise. Isto ocorre devido à diminuição da massa de carvão sem a correspondente diminuição da massa de cinza, uma vez que esta última, segundo ANDRADE (1989), só é degradada em temperaturas acima dos $1200^{\circ} \mathrm{C}$.
São observados aumentos significativos nos teores de carbono fixo à medida que se eleva a temperatura máxima de pirólise. Os maiores teores de carbono fixo foram apresentados pelos carvões das madeiras de eucalipto (E. grandis) e pau-jacaré (P. gonoacantha), pirolisadas à temperatura máxima de $600{ }^{\circ} \mathrm{C}(87,40 \%$ e 87,20 \%, respectivamente). Por outro lado, o menor teor de carbono fixo foi apresentado pelo carvão da madeira de leucena (L. leucocephala), pirolisada à temperatura máxima de $400{ }^{\circ} \mathrm{C}(71,20 \%)$.

Os rendimentos em carbono fixo dos carvões, produto dos respectivos rendimentos em carvão e teores de carbono fixo, apresentaram valores médios distribuídos num intervalo de $21,46 \%$ a $22,83 \%$. De acordo com ANDRADE \& CARVALHO (1998), o rendimento em carbono fixo é um dos parâmetros que melhor expressam a qualidade da matéria-prima lenhosa para a produção de carvão vegetal. Para os referidos autores, quanto maior for o rendimento em carbono fixo, melhor será a qualidade da biomassa para fins energéticos. Os rendimentos em carbono fixo dos carvões da madeira de pau-jacaré ( $P$. gonoacantha), pirolisada a $400{ }^{\circ} \mathrm{C}$ e $600{ }^{\circ} \mathrm{C}$, foram os dois maiores observados na presente pesquisa.

\section{CONCLUSÕES}

Com base nos resultados da pesquisa foi possível chegar às seguintes conclusões:

1. Existe uma tendência à diminuição do rendimento em carvão vegetal à medida que se 
eleva a temperatura máxima de pirólise.

2.Os rendimentos em carvão das madeiras de pau-jacaré ( $P$. gonoacantha) e de leucena ( $L$. leucocephala), pirolisadas à temperatura máxima de $400^{\circ} \mathrm{C}$, foram superiores aos demais ora analisados.

3. Existe uma tendência à diminuição do teor de matérias voláteis no carvão à medida que se eleva a temperatura máxima de pirólise.

4.Há uma ligeira tendência ao aumento no teor de cinza no carvão à medida que se eleva a temperatura máxima de pirólise.

5.Existe uma tendência ao aumento do teor de carbono fixo do carvão à medida que se eleva a temperatura máxima de pirólise.

6. Os rendimentos em carbono fixo dos carvões da madeira de pau-jacaré ( $P$. gonoacantha), pirolisada a $400^{\circ} \mathrm{C}$ e $600^{\circ} \mathrm{C}$, foram os maiores observados na presente pesquisa.

\section{REFERÊNCIAS}

ABRACAVE - Associação Brasileira dos Recursos Naturais Renováveis. Anuário Estatístico / 98. Belo Horizonte, MG, 2000. 12p.

ANDRADE, A.M.de \& CARVALHO, L.M. de. Potencialidades energéticas de oito espécies florestais do Estado do Rio de Janeiro. Instituto de Florestas, Universidade Federal Rural do Rio de Janeiro, Seropédica, RJ, Floresta e Ambiente, 5(1): 24-42, jan./ dez., 1998.

ANDRADE, A.M.de. Efeitos da fertilização mineral e da calagem na produção e na qualidade da madeira e do carvão de eucalipto. 1993. 105p. (Tese de doutorado), Universidade Federal de Viçosa (UFV), Viçosa, MG.

ANDRADE, A.M.de. Influência da casca de Eucalyptus grandis W.Hill ex Maiden no rendimento e qualidade de carvão vegetal. Viçosa, MG, Universidade Federal de Viçosa - UFV, 1989.

ANDRADE, A.M.de. Tecnologia química dos produtos florestais. Seropédica, RJ, UFRRJ - Universidade Federal Rural do Rio de Janeiro, Imprensa Universitária, p.109-111, 1993. (SPT).

ASTM - American Society for Testing and Materials. Standard method for chemical analyses of wood charcol. Phyladelphia, 1977. 1042p.

BRITO, J.O. Princípios de produção e utilização de carvão vegetal de madeira. Piracicaba, SP, Documentos Florestais, (9): 1-19, mai. 1990. 19p.

INFOTEC/PRÓ-CARVÃO - Informativo Técnico do Programa de Qualificação da Cadeia Produtiva do Carvão Vegetal do Estado de São Paulo. Carbonização da madeira e produtos obtidos. Piracicaba, SP, n. 1, ano 1, 2000.

INFOTEC/PRÓ-CARVÃO - Informativo Técnico do Programa de Qualificação da Cadeia Produtiva do Carvão Vegetal do Estado de São Paulo. Carvão vegetal de eucalipto. Piracicaba, SP, n. 4, ano 2, 2001.

NOGUEIRA, L.A.H.; LORA, E.E.S.; TROSSERO, M.A.; FRISK, T. Dendroenergia: fundamentos e aplicações. Brasília, DF, 2000. 144p.

OLIVEIRA, J.B.; GOMES, P.A.; ALMEIDA, M.R. Propriedades do carvão vegetal. In: PENEDO, W.R. Carvão vegetal. Belo Horizonte, MG, CETEC - Centro Tecnológico de Minas Gerais, p.9-61, 1982 (SPT).

VITAL, B.R. Métodos de determinação da densidade da madeira. Viçosa, MG, SIF - Sociedade de Investigações Florestais, 1984. 21p. (Boletim Técnico 01). 